\title{
Synthesis of magnetic multiwalled carbon nano tubes and investigation of isotherm and kinetic models for cleanup of carbaryl pesticide
}

\author{
Khaghani R. ${ }^{1}$, Esrafili A. ${ }^{2}$, Zeynalzadeh D. ${ }^{3,4^{*}}$ and AsI F.B. ${ }^{5}$ \\ ${ }^{1}$ School of medicine, AJA University of Medical Sciences, Tehran, Iran \\ 2Department of Environmental Health Engineering, Faculty of Public Health, Iran University of Medical Sciences, Tehran, Iran \\ ${ }^{3}$ Researcher, School of Medicine, AJA University of Medical Sciences, Tehran, Iran \\ ${ }^{4}$ Department of Environmental Health Engineering, Faculty of Public Health, Tehran University of Medical Sciences, Tehran, Iran \\ ${ }^{5}$ Department of Environmental Health Engineering, School of Public Health, Urmia University of Medical Sciences, Urmia, Iran \\ Received: 25/09/2018, Accepted: 03/07/2020, Available online: 10/07/2020 \\ *to whom all correspondence should be addressed: e-mail: d.zeynalzadeh@yahoo.com \\ https://doi.org/10.30955/gnj.002895
}

\section{Graphical abstract}

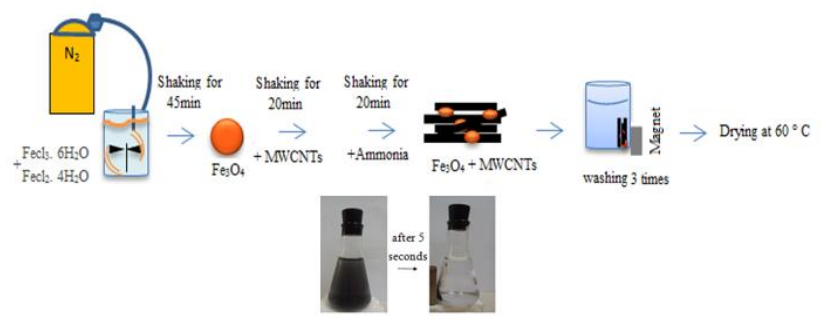

\section{Abstract}

Water is the main factor of movement and transport of pesticides and contamination of water by these pollutants is one of the most important challenges due to their widespread use and increased concentrations. Moreover, these compounds are on the U.S.EPA Priority Pollutant list because of the potential of accumulation and the property of damaging effects. In this study, multiwalled carbon nanotube-based magnetic nanoparticles were synthesized and used as an affective adsorbent for carbaryl pesticide. The properties of the synthesized $\mathrm{Fe}_{3} \mathrm{O}_{4} @ M W C N T s$ were characterized by TEM images and XRD analysis. The obtained data were studied by isotherm and kinetic models. Carbaryl adsorbed onto the synthesized adsorbent was compatible with the Langmuir isotherm $\left(R^{2}=0.993\right)$. The maximum adsorption capacity $\left(q_{\max }\right)$ of the pesticide onto the $\mathrm{Fe}_{3} \mathrm{O}_{4}$-MWCNTs was obtained at 68.2 $\mathrm{mg} / \mathrm{g}$. The kinetic studies of the reactions showed that the adsorption process followed the pseudo-second order model with $R^{2} \geq 0.99$ for all initial carbaryl concentrations. The adsorbent was extracted by magnet reused several times (six rounds) with a reasonable efficiency. The $\mathrm{Fe}_{3} \mathrm{O}_{4}$ MWCNTs have great potential for adsorption of carbaryl from water and wastewater due to high efficiency, easy separation and reusability.

Keywords: Adsorption, carbon nanotube, carbaryl, kinetic, isotherm.

\section{Introduction}

Carbamates are one of the major classes of the pesticides, which are widely used in agriculture against insects, fungi and weeds (Wu et al., 2010; Liu et al., 2009). These compounds are potentially hazardous to the environment and human health. Carbaryl (1-naphthyl-Nmethyl carbamate) (Scheme 1), which is a broad-spectrum insecticide, is used to control more than 100 species of insects in fruits, forests, lawns, domestic vegetables and other crops (Melchert and Rocha, 2010; Zhu et al., 2009). This compound, because of their ability to accumulate and their long-term effects on living organisms, is on the priory list released by the USEPA (United States Environmental Protection Agency) (Chin-Chen et al., 2012; Alavanja et al., 2004; Liu et al., 2013). The potential risks of human health owing to the contact with pesticides are noticeably seen through the detection of pesticide compounds residues in water, foodstuffs and even in breast milk (El Ouardi et al., 2013). Carbaryl can cause adverse effects on humans with inhalation, skin contact, or ingestion (Chin-Chen et al., 2012). Exposure to this substance, in addition to its teratogenic characteristics, inhibits the cholinesterase enzyme, impairing the functions of the central nervous system and can cause nausea, vomit, broncho-constriction, blurred vision, convulsions, coma and respiratory failure (Chowdhury et al., 2012; Melchert and Rocha, 2010; Liu et al., 2013).

In soil, carbaryl is bounded by organic materials and can be transported (Ghauch et al., 2001). Removal of these organic pollutants during water treatment has been tested through nanofiltration (Boussahel et al., 2000), ozonation (Kusvuran et al., 2012) and some of adsorbents such as activated carbon (El Ouardi et al., 2013; Zhang et al., 2012; Meyers et al., 2013; Chen et al., 2009). However, these techniques have some disadvantages like rapidly saturated for some adsorbents and generated byproducts. Carbon nanotubes (CNTs), due to their high surface area, have long 
been employed as adsorbents for trapping or separation of some contaminants from aquatic environments. But their large-scale application has somewhat been limited owing to the problems in separating materials (products and residual sorbents) from solution (Jiang et al., 2009; Wu et al., 2011). CNTs display excellent mechanical, electrical and magnetic properties (Sahoo et al., 2010).

Recently, the magnetic separation method has been applied due to its low cost, economic aspects, biodegradability, non-toxicity, simplicity and being quick in separation (Kakavandi et al., 2013; Prucek et al., 2011; Mi et al., 2011; Dong et al., 2012). In this study, we synthesized and used super paramagnetic $\mathrm{Fe}_{3} \mathrm{O}_{4}$ nanoparticles in order to produce magnetic separation characteristic for MWCNTs (Multi Walled Carbon Nano Tubes).

Moreover, the mechanisms of adsorption of solutions of carbaryl, as an effluent model, and magnetic MWCNTs, as the adsorbents, were chosen to be studied. Therefore, after Carbaryl sorption onto the $\mathrm{Fe}_{3} \mathrm{O}_{4}$-MWCNTs nanoparticles, the adsorbents could be readily separated from water solution with an external magnetic field. The basic objectives of the present work were as follows: (1) synthesizing $\mathrm{Fe}_{3} \mathrm{O}_{4}-\mathrm{MWCNTs}$ and presenting its properties, (2) investigating the adsorption kinetics and analyzing the experimental data with the pseudo-first-order and pseudosecond-order equations, (3) investigating the adsorption isotherms and analyzing experimental data with the Langmuir, Freundlich and BET models and (4) implementing reuse of $\mathrm{Fe}_{3} \mathrm{O}_{4}-\mathrm{MWCNTs}$ after adsorption.

\section{Experimental}

\subsection{Adsorbate}

Technical grade Carbaryl $\left(\mathrm{C}_{12} \mathrm{H}_{11} \mathrm{NO}_{2}\right)$ of $99.9 \%$ purity supplied by Sigma-Aldrich was used as an adsorbate. The structure of the insecticide has been shown in Scheme 1. Distilled water was used to prepare all solutions.

\subsection{Material}

Multiwalled carbon nanotubes were prepared from nano US Company, ferric chloride hexahydrate $\left(\mathrm{Fecl}_{3} \cdot 6 \mathrm{H}_{2} \mathrm{O}\right)$, ferrous chloride tetrahydrate $\left(\mathrm{Fecl}_{2} \cdot 4 \mathrm{H}_{2} \mathrm{O}\right)$ and ammonia were purchased from Merck (Germany).

\subsection{Apparatus}

The HPLC (High-performance liquid chromatography), assembled from modular components (CECIL, CE4100, England), consisted of an in-line degasser, a 600E pump and a UV-visible detector (CE4200, CECIL, England). The injection loop volume was $30 \mu \mathrm{L}$. A $\mathrm{C}_{18 \mathrm{ec}}$ column (250 mm $\times 4.6 \mathrm{~mm}$ I.D., 5.0 $\mu \mathrm{m}$ ) MACHERY-NAGEL (German Quality) was used for separations. The mobile phase was a combination of methanol-water $(70: 30, v / v)$ at the flow rate of $1 \mathrm{~mL} / \mathrm{min}$. UV detector wavelengths were selected at $220 \mathrm{~nm}$ for carbaryl. The identification of carbaryl was made by retention times and ultraviolet absorption spectra detection. The peak area of the analyte was used for quantification.

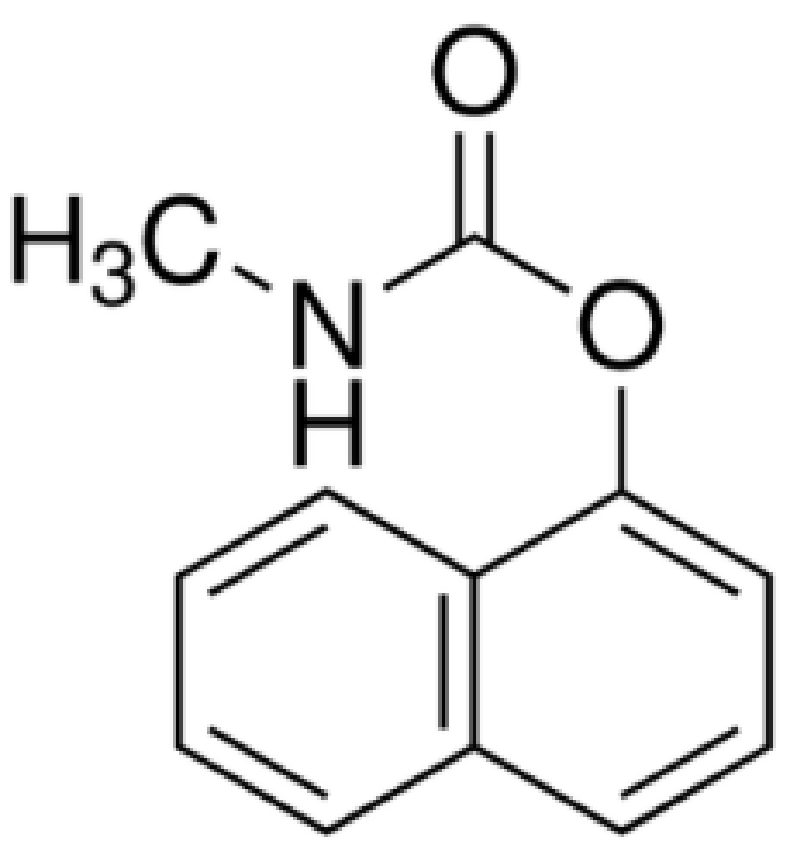

Scheme 1. Chemical structure of Carbaryl

The morphology of MWCNTs and $\mathrm{Fe}_{3} \mathrm{O}_{4}-\mathrm{MWCNTs}$ was characterized by transmission electron microscope (TEM) images (obtained with EM 208-Philips operated at an acceleration voltage of $100 \mathrm{kV}$ ). X-ray diffraction (XRD) measurement was performed using a Bruker D8Advance (CuK, radiation with $1.5416 \mathrm{~A}^{\circ}$ wavelengths) diffractometer. In order to do magnetic separation of adsorbent from aqueous solution, we used a magnetic field with the intensity of $1.3 \mathrm{~T}$; and, a $\mathrm{pH}$ meter (HACH-HQ-USA) was used to control solution $\mathrm{pH}( \pm 0.01)$.

\subsection{Synthesis of $\mathrm{Fe}_{3} \mathrm{O}_{4}-\mathrm{CNTS}$}

Magnetic carbon Nanotubes were synthesized by a coprecipitation method. $\mathrm{FeCl}_{3} .6 \mathrm{H}_{2} \mathrm{O}(8.48 \mathrm{gr})$ and $\mathrm{Fecl}_{2} 4 \mathrm{H}_{2} \mathrm{O}$ ( $2.25 \mathrm{gr}$ ) were dissolved in $400 \mathrm{ml}$ water and mixed by mechanical stirring; then, the samples were heated at $75^{\circ} \mathrm{C}$ within $45 \mathrm{~min}$ under nitrogen gas. Next, after homogenization in ultrasonic, $10 \mathrm{gr}$ MWCNTs, were added to the solution and kept for $20 \mathrm{~min}$. Afterwards, $20 \mathrm{ml}$ ammonia was added to the solution. After $20 \mathrm{~min}$, the $\mathrm{Fe}_{3} \mathrm{O}_{4}$-MWCNTs were separated with an external magnet and washed three times with distilled water. Finally, the nanoparticles were dried in a vacuum oven at $60{ }^{\circ} \mathrm{C}$ within 6 hours. The preparation procedure of the magnetic carbon nanotubes has been illustrated in Figure 1.

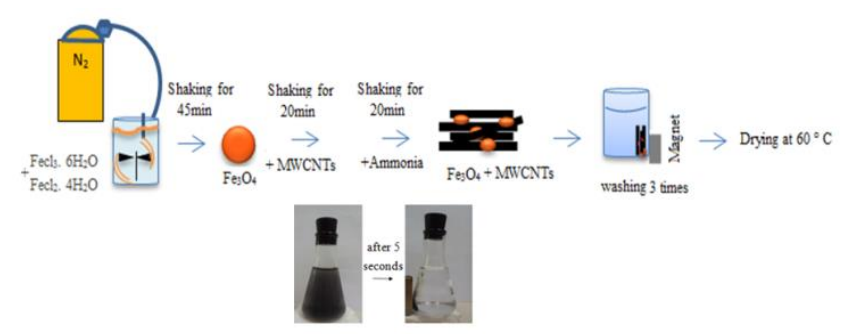

Figure 1. Steps of synthesis of $\mathrm{Fe}_{3} \mathrm{O}_{4}-\mathrm{MWCNTs}$ magnetic Nano composites 


\subsection{Adsorption kinetic and isotherm study}

The parameters investigated in the current study were $\mathrm{pH}$, adsorbent dose ( $\left.\mathrm{Fe}_{3} \mathrm{O}_{4}-\mathrm{MWCNTS}\right)$, initial carbaryl concentration and contact time. For kinetic studies, a series of $100-\mathrm{mL}$ Erlenmeyer flasks were filled with $50 \mathrm{~mL}$ the pesticide solution at the concentration of $10 \mathrm{mg} / \mathrm{L}$. The $\mathrm{pH}$ of the solution was kept at 6 by adding $0.1 \mathrm{M} \mathrm{NaOH}$ or $0.1 \mathrm{M}$ $\mathrm{HNO}_{3}$. An equal amount of the adsorbent $(0.2 \mathrm{~g} / \mathrm{L})$ was added separately to each flask. The agitation speed was kept constant at $150 \mathrm{rpm}$. At predetermined intervals of time $(5,10,15,20,25,30,60$ and $120 \mathrm{~min}), \mathrm{Fe}_{3} \mathrm{O}_{4}-\mathrm{MWCNTs}$ were separated from the solution by an external magnet field.

Adsorption isotherm experiments were conducted by adding $50 \mathrm{~mL}$ of the solution containing $10 \mathrm{mg} / \mathrm{L}$ pesticide to different concentrations of the adsorbent $(0.1,0.15,0.2$, $0.25,0.3$ and $0.5 \mathrm{~g} / \mathrm{L}$ ). The mixtures were kept until $30 \mathrm{~min}$ at the $\mathrm{pH}$ value of 6 .

The standard coefficient of determination $\left(R^{2}\right)$ was employed to compare the amount of fitting between prediction models and measured data.

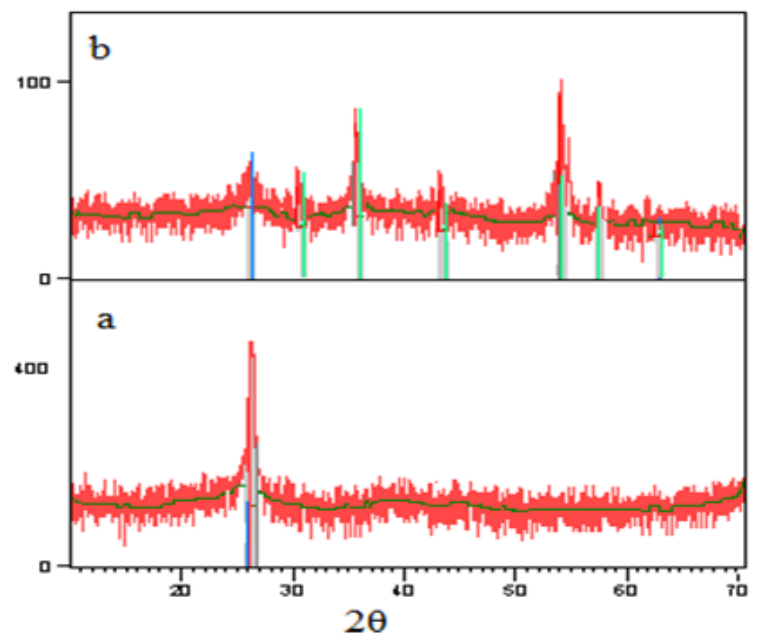

Figure 2. X-ray diffraction pattern of (a) MWCNT and (b) $\mathrm{Fe}_{3} \mathrm{O}_{4}-$ MWCNT

\section{Result and discussion}

\subsection{Characterization of magnetic carbon nanotubes}

X-ray diffraction (XRD) measurements were employed to investigate the phase and structure of the MWCNTs and synthesized $\mathrm{Fe}_{3} \mathrm{O}_{4}-\mathrm{MWCNTS}$. Diffraction peaks assigned to MWCNTs at $2 \theta=26.5^{\circ}$ (Figure 2a) can be clearly seen in the XRD curves of pure MWCNT (Wang et al., 2008), and the $\mathrm{Fe}_{3} \mathrm{O}_{4}-\mathrm{MWCNT}$ composite indicating the MWCNT structure was not destroyed after the successive deposition of $\mathrm{Fe}_{3} \mathrm{O}_{4}$. From Figure $2 \mathrm{~b}$, except for the diffraction peak at $2 \theta=26.5^{\circ}$ resulting from MWCNTs, all the new significant diffraction peaks of the $\mathrm{Fe}_{3} \mathrm{O}_{4}-\mathrm{MWCNT}$, which are matched well with the data for $\mathrm{Fe}_{3} \mathrm{O}_{4}: 30.2^{\circ}, 35.6^{\circ}, 43.3^{\circ}, 53.7^{\circ}, 57.3^{\circ}$, and $62.8^{\circ}$, can be assigned to (2 2 0), (3 11 1), (4 00 ), (4 22 2), (5 11 ), and (4 40 ) of the crystal indices for $\mathrm{Fe}_{3} \mathrm{O}_{4}$, respectively.
TEM images of MWCNTs and $\mathrm{Fe}_{3} \mathrm{O}_{4}-\mathrm{MWCNTs}$ have been shown in Figure 3. The outer diameters of those tubes are in the approximate range of $10-30 \mathrm{~nm}$. As shown in Figure $3 b$, the iron oxide nanoparticles were coated on the surface of MWCNTs to form $\mathrm{Fe}_{3} \mathrm{O}_{4}-\mathrm{MWCNTS}$. The $\mathrm{Fe}_{3} \mathrm{O}_{4}$ nanoparticles were properly distributed on the surface of the carbon tubes.

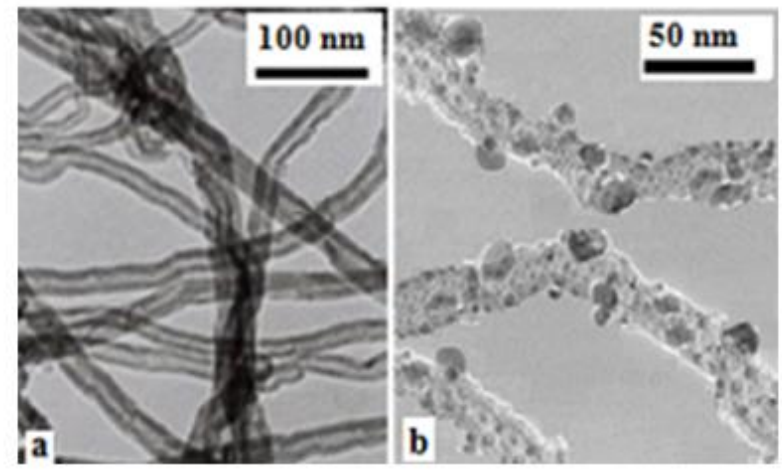

Figure 3. TEM images of (a) MWCNTs and (b) $\mathrm{Fe}_{3} \mathrm{O}_{4}-\mathrm{MWCNTS}$

\subsection{Adsorption isotherms modeling}

Three isotherms: Langmuir, Freundlich and BrunauerEmmett-Teller (BET) were tested for their ability for description of the experimental results. The Langmuir isotherm is founded on the assumption that the adsorption process takes place on homogenous adsorbent surfaces (Kakavandi et al., 2013). This model assumes that maximum adsorption corresponds to a saturated monolayer of solute molecules on the surface of the adsorbent, with no lateral interaction among the sorbed molecules. The linear equation of the Langmuir model is shown as Eq. 1:

$$
\frac{1}{q_{e}}=\frac{1}{q_{\max }}+\frac{1}{b C_{e} q_{\max }}
$$

Where $q_{\mathrm{e}}(\mathrm{mg} / \mathrm{g})$ is the amount of sorbed molecules per unit mass of the adsorbent, $C_{e}(\mathrm{mg} / \mathrm{L})$ is the adsorbate concentration at equilibrium, $q_{\max }(\mathrm{mg} / \mathrm{g})$ is the maximum amount of the adsorbate per unit mass of adsorbent when complete monolayer bound at high $C_{\mathrm{e}}$ and $b(\mathrm{~L} / \mathrm{mg})$ is the Langmuir constant. Figure 4 shows that the adsorption of carbaryl onto $\mathrm{Fe}_{3} \mathrm{O}_{4}-\mathrm{MWCNTS}$ was best fitted to the Langmuir model. The Langmuir constants (b) and $q_{\max }$ were obtained from the intercept and slope of the plot. Characteristics of the Langmuir model can be descripted with the $R_{\mathrm{L}}$ factor as shown in Eq. 2 (Hameed, Salman, and Ahmad, 2009):

$$
\mathrm{R}_{\mathrm{L}}=\frac{1}{1+b c_{0}}
$$

Where $C_{0}$ is the maximum initial dose of the adsorbate $(\mathrm{mg} / \mathrm{L})$. The factor of $R \mathrm{~L}$ represents the condition of the isotherm to be irreversible $(R L=0)$, favorable $(0<R L>1)$, linear adsorption $(R L=1)$ and unfavorable $(R L>1)$. The value of $R \mathrm{~L}$ in the present investigation was found to be 0.33 indicating that the adsorption of carbaryl onto $\mathrm{Fe}_{3} \mathrm{O}_{4}$ MWCNTs is favorable. 


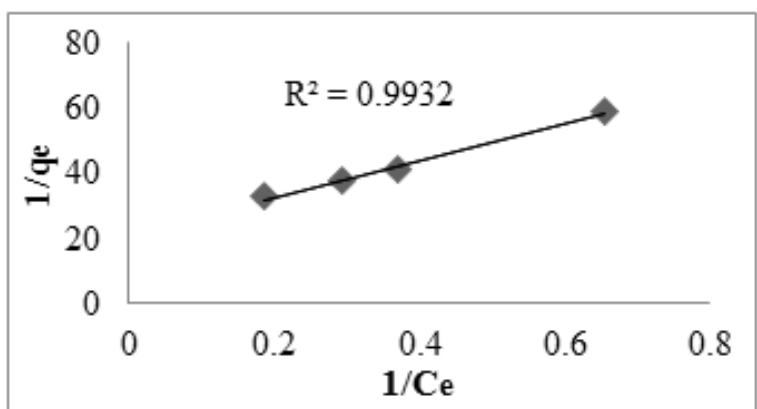

Figure 4. Langmuir adsorption isotherm of Carbaryl on $\mathrm{Fe}_{3} \mathrm{O}_{4}$ CNTs

The BET model (Classics Brunauer et al., 1938) is a development of the Langmuir model for multilayer adsorption. The BET isotherm is a theoretical equation and are commonly employed in the gas-solid equilibrium processes. It assumes that each adsorbate in the first adsorbed layer serves as an adsorption site for the second layer and so forth (Ofomaja et al., 2010). In this study, this model was used to calculate Carbaryl sorption based on Eq. (3):

$$
\frac{c_{e}}{\left(c_{s}-c_{e}\right) q}=\frac{1}{K_{B E T} q_{m}}+\left(\frac{K_{B E T}-1}{K_{B E T} q_{m}}\right)\left(\frac{c_{e}}{c_{s}}\right)
$$

where $K_{\mathrm{BET}}, c_{\mathrm{s}}, q_{\mathrm{m}}$ and $q$ are the constant expressive of energy of interaction with the surface, adsorbate monolayer saturation concentration $(\mathrm{mg} / \mathrm{L})$, theoretical isotherm saturation capacity $(\mathrm{mg} / \mathrm{g})$ and equilibrium adsorption capacity $(\mathrm{mg} / \mathrm{g})$, respectively. A plot of $C_{\mathrm{e}} /\left(C_{\mathrm{s}}-\right.$ $\left.C_{e}\right) q$ against $\left(C_{e} / C_{s}\right)$ should give a straight line. The values of $K_{\mathrm{BET}}$ and $q_{\mathrm{m}}$ can be calculated from the slope and intercept (Figure 5).

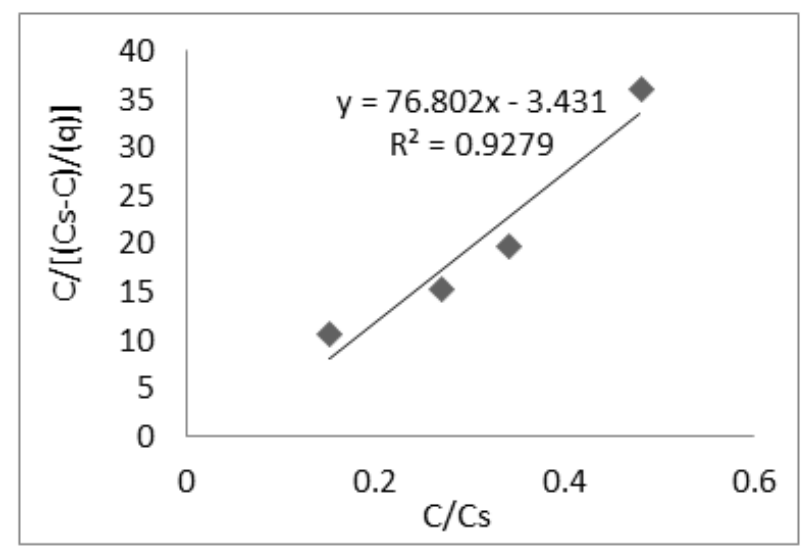

Figure 5. BET adsorption isotherm of Carbaryl on $\mathrm{Fe}_{3} \mathrm{O}_{4}$-CNTs

The third model is the Freundlich approach; according to this model, the uptake of sorbate fall out on a heterogeneous surface by multilayer sorption (Freundlich and Hatfield, 1926). The linear form of this model is presented by Eq. 4.

$$
\operatorname{Ln} \mathrm{q}_{\mathrm{e}}=\ln \mathrm{K}_{\mathrm{f}}+\frac{1}{\mathrm{n}} \ln \mathrm{C}_{\mathrm{e}}
$$

Where $\mathrm{K}_{\mathrm{F}}(\mathrm{L} / \mathrm{g})$ is the constant showing the relative adsorption capacity of the adsorbent and $1 / n$ is the intensity of the adsorption. $\mathrm{K}_{\mathrm{F}}$ and $\mathrm{n}$ are calculated from the intercept and slope of the plot.

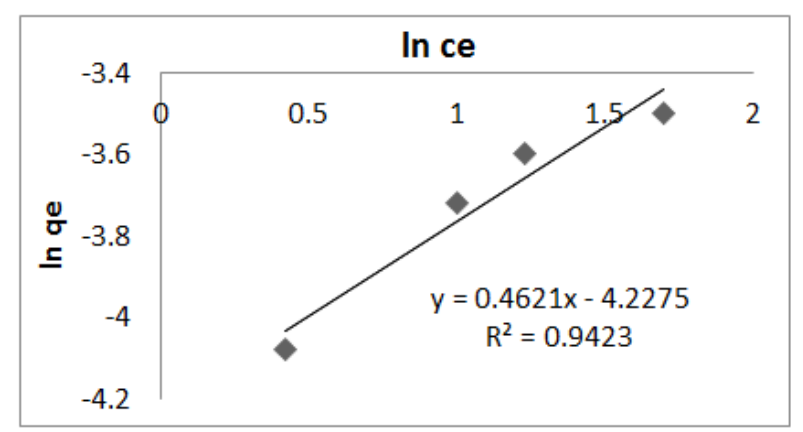

Figure 6. Freundlich adsorption isotherm of Carbaryl on $\mathrm{Fe}_{3} \mathrm{O}_{4-}$ MWCNTS

As can be seen from Table 1, the Freundlich model does not fit well the experimental data $\left(R^{2}<0.95\right)$. Thus, carbaryl adsorption onto the magnetic carbon nanotubes cannot be expressed by the Freundlich isotherm. For the Freundlich isotherm model, the value of $n$ was greater than 1 illustrating that the adsorption process followed a normal Langmuir isotherm. This shows homogeneous magnetic carbon nanotube surface in which the carbaryl molecule and carbon nanotubes had equal adsorption activation energy (Salman and Hameed, 2010).

The correlation coefficient ( $R^{2}$ values) was used to judge the applicability of the isotherm equation. As seen in Table 1, the Langmuir isotherm was best fitted to the experimental data while fitting the Freundlich isotherm represents a multilayer adsorption and the BET isotherm, which is an extension of the Langmuir isotherm, shows that multilayer sorption is not as good as the Langmuir model for carbaryl toxin adsorption.

Table 1. Isotherm parameters for removal of Carbaryl by $\mathrm{Fe}_{3} \mathrm{O}_{4}-$ CNTs

\begin{tabular}{cc}
\hline Isotherm & Parameters \\
\hline Langmuir & \\
\hline $\mathrm{q}_{\max }(\mathrm{mg} / \mathrm{g})$ & 68.2 \\
\hline $\mathrm{b}(\mathrm{L} / \mathrm{mg})$ & 0.212 \\
\hline $\mathrm{R}^{2}$ & 0.9932 \\
\hline Freundlich & \\
\hline $\mathrm{K}_{\mathrm{f}}$ & 12.64 \\
\hline $\mathrm{n}$ & 1.51 \\
\hline $\mathrm{R}^{2}$ & 0.9423 \\
\hline $\mathrm{BET}$ & \\
\hline $\mathrm{K}_{\mathrm{BET}}$ & 20.847 \\
\hline $\mathrm{q}_{\mathrm{m}}$ & 18.783 \\
\hline $\mathrm{R}^{2}$ & 0.9279 \\
\hline
\end{tabular}

The adsorption isotherm models fitted the data in the order of: Langmuir $>$ Freundlich $>$ BET isotherm.

\subsection{Comparison of carbaryl adsorption capacity among different adsorbents}

Table 2 compares the adsorption capacity of different types of adsorbents reported in the literature for adsorption of some pesticides. It is apparent that recycled $\mathrm{Fe}_{3} \mathrm{O}_{4}$ - 
MWCNTs are very useful adsorbent for carbaryl removal from aqueous solutions. The value of $q_{\max }$ in this study is larger than that in most of previous works.

Table 2. Comparison of adsorption capacity of different pesticides mentioned in this work and previous studies

\begin{tabular}{ccccc}
\hline Pesticide & Adsorbent & Qmax & $\mathbf{R}^{\mathbf{2}}$ & Reference \\
\hline Carbaryl & $\mathrm{Fe}_{3} \mathrm{O}_{4}$-MWCNTs & 68.2 & 0.993 & The current study \\
\hline Carbaryl & Clay & 10.75 & 0.97 & (Mahmoud El et al., 2013) \\
\hline Methyl parathion & Activated carbon & 97.09 & 0.998 & (Gupta et al., 2011) \\
\hline Atrazine & Activated carbon & 95.24 & 0.995 & (Gupta et al., 2011) \\
\hline Methoxychlor & Activated carbon & 66.67 & 0.995 & (Gupta et al., 2011) \\
\hline Deltamethrin & Oil shale ash & 10.74 & 0.997 & (Al-Qodah et al., 2007) \\
\hline Paraquat dichloride & Pyrolysis and activation of & 27.8 & 0.991 & (Hamadi et al., 2004) \\
\hline 8-quinolinecarboxylic acid & Sodium montmorillonite & 65.4 & 0.98 & (Mekhloufi et al., 2013) \\
\hline 8-quinolinecarboxylic acid & $\begin{array}{c}\text { Organic-acidic } \\
\text { montmorillonite }\end{array}$ & 75.9 & 0.99 & (Mekhloufi et al., 2013) \\
\hline Carbaforan & Banana stalks activated & 161.3 & 0.989 & (Salman and Hameed, 2010) \\
\hline Aldrin & carbon & & \\
\hline Dieldrin & Acid-treated date stones & 6.37 & 0.913 & (El Bakouri et al., 2009) \\
\hline Endrin & Acid-treated date stones & 6.97 & 0.901 & (El Bakouri et al., 2009) \\
\hline & Acid-treated date stones & 5.98 & 0.924 & (El Bakouri et al., 2009) \\
\hline
\end{tabular}

\subsection{Adsorption kinetic modeling}

This study examined the kinetics of carbaryl removal from solutions by magnetic carbon nanotubes through the pseudo-first order and second order kinetic models as shown in Eqs. (5) and (6), respectively (Prucek et al., 2011).

$$
\begin{aligned}
& \log \left(\mathrm{q}_{\mathrm{e}}-\mathrm{q}_{\mathrm{t}}\right)=\log \mathrm{q}_{\mathrm{e}}-\frac{k_{1}}{2.303} \mathrm{t} \\
& \frac{t}{q_{\mathrm{t}}}=\frac{1}{k_{2} q_{e}^{2}}+\frac{t}{q_{e}}
\end{aligned}
$$

This suggests that carbaryl could easily be adsorbed by the magnetic nanotubes. 
hydrolysis, complexation of ligands, redox reactions and precipitation are highly affected with $\mathrm{pH}$ (Mahapatra et al., 2013). The pesticide adsorption onto $\mathrm{Fe}_{3} \mathrm{O}_{4}-\mathrm{MWCNTs}$ increased abruptly at $\mathrm{pH}$ ranging from 2 to 4; then, it increased slowly at $\mathrm{pH}$ from 4 to 10 . At lower $\mathrm{pH}$, the concentration of $\mathrm{H}^{+}$ion is high. Thus, it significantly influenced the protonation-deprotonation transition of MWCNT surface groups like $-\mathrm{OH}$ and $-\mathrm{COOH}$, resulting in a competition for vacant adsorbent sites between $\mathrm{H}^{+}$ion and adsorbate molecules; for this reason, at low $\mathrm{pH}$, the removal efficiency is low. Yang et al., claimed a similar $\mathrm{pH}$ effect on adsorption phenolic compounds adsorption trend by means of MWCNTs adsorbent (Yang et al., 2008).

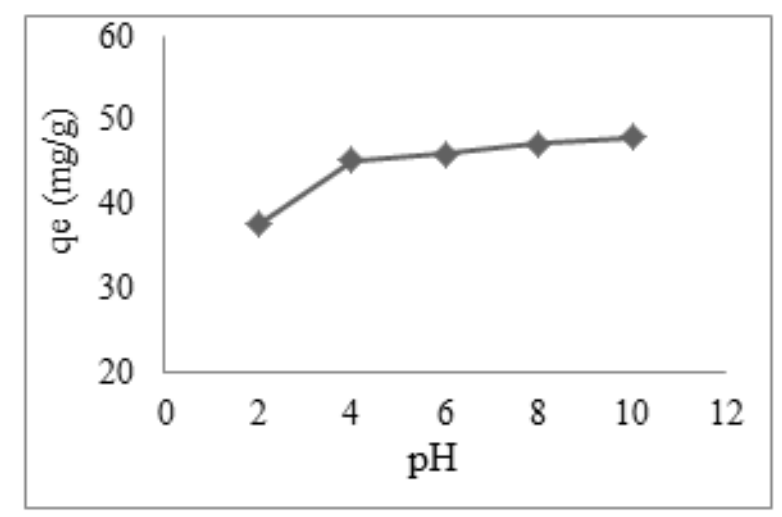

Figure 8. Effect of solution $\mathrm{pH}$ on the uptake of Carbaryl

\subsection{Effect of contact time and initial concentration on carbaryl adsorption}

The effects of time and initial concentration of carbaryl on the uptake using magnetic carbon nano tubes have been presented in Figure 9. The equilibrium was achieved at $30 \mathrm{~min}$ for carbaryl adsorption onto $\mathrm{Fe}_{3} \mathrm{O}_{4}-\mathrm{MWCNTs}$. The time of equilibration adsorption was unaffected with initial concentration, but the amount adsorbed increased by increasing initial concentration of the pesticide. An increase in adsorption was observed from 24, 35.2 and $90 \mathrm{mg} / \mathrm{g}$ for initial concentrations of 5, 10 and $20 \mathrm{mg} / \mathrm{L}$, respectively. This illustrates that initial concentration is very important in carbaryl adsorption on $\mathrm{Fe}_{3} \mathrm{O}_{4}-\mathrm{MWCNTs}$. This is due to the fact that, at higher initial concentrations, carbaryl has to diffuse to the inner sites of the carbon nano tubes. Gubta et al. (Gupta et al., 2011) investigated the effect of the parameter initial concentration on adsorption of pesticides by activated carbon and they reported similar observations.

\subsection{Reusability of $\mathrm{Fe}_{3} \mathrm{O}_{4}-\mathrm{MWCNTS}$}

The main objective of the reuse process is to restore the adsorption capacity of an exhausted adsorbent. The repeated availability of $\mathrm{Fe}_{3} \mathrm{O}_{4}-\mathrm{MWCNTS}$ for carbaryl adsorption from aqueous solution through many cycles of adsorption/desorption is quite crucial for the application of magnetic MWCNTs in the removal of pesticides from solution in real work. In this study, the reuse of $\mathrm{Fe}_{3} \mathrm{O}_{4}$ MWCNTs, each time after washing with distilled water, in the removal of carbaryl from aqueous solution was examined. Adsorption cycles repeated five times by using the same adsorbent for the new samples of the pesticide. Figure 10 presents adsorption percentages after reuse.

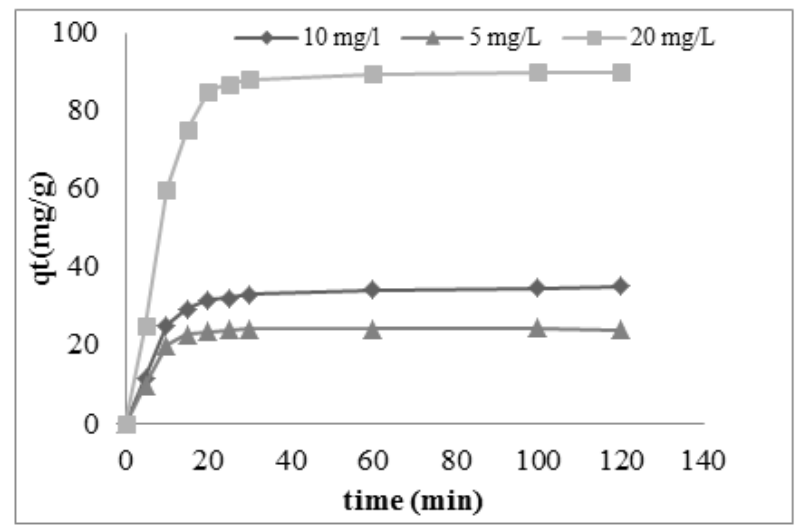

Figure 9. Effect of initial concentration of Carbaryl adsorption onto $\mathrm{Fe}_{3} \mathrm{O}_{4}$ - MWCNTs. Lines represents the model fitting of pseudo-second-order equation

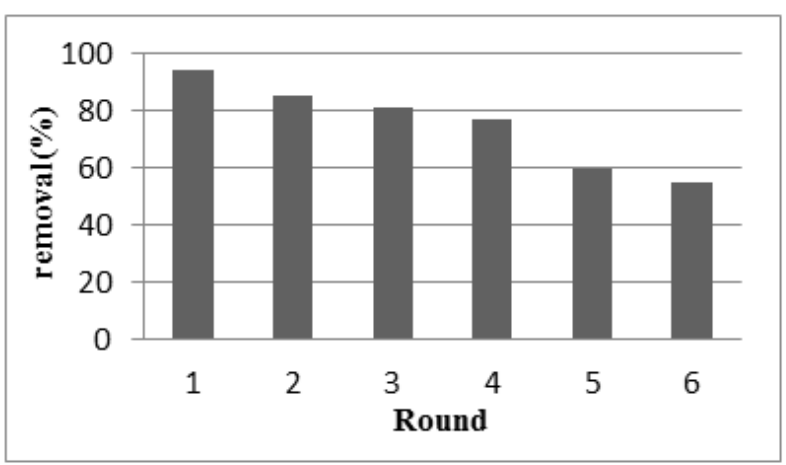

Figure 10. Recycling use of $\mathrm{Fe}_{3} \mathrm{O}_{4}$-MWCNTs in the removal of Carbaryl from aqueous solution

It is observed that the adsorption percentage of carbaryl declined from 94 to $77 \%$ with increasing the times of the reuse. The removal efficiency of the pesticide onto $\mathrm{Fe}_{3} \mathrm{O}_{4}-$ MWCNTs was well after reuse for four times, which illustrates that the MWCNTs have a very good reusability.

\section{Conclusion}

Multi-walled carbon nano tube-based magnetic nanocomposite was synthesized and it was used as an effective adsorbent for carbaryl pesticide for the first time. The XRD analysis and TEM images of the CNTs and $\mathrm{Fe}_{3} \mathrm{O}_{4}-$ MWCNTs confirm the formation of the synthesized nanocomposite. The equilibrium data were fitted to the Langmuir, Freundlich and BET isotherm models. The suitability of the kinetic models for the adsorption of the pesticide was also discussed. It was found that the adsorption kinetics obeyed the pseudo-second-order adsorption kinetic model. After sorption, the adsorbent can be extracted and be efficiently reused for many cycles.

\section{References}

Alavanja M.C.R., Jane A.H. and Freya K. (2004), Health Effects of Chronic Pesticide Exposure: Cancer and Neurotoxicity* 3, Annu. Rev. Public Health, 25, 155-197. 
Al-Qodah Z., Shawaqfeh A.T. and Lafi W.K. (2007), Adsorption of pesticides from aqueous solutions using oil shale ash, Desalination, 208, 294-305.

Bakouri El., Usero H.J., Morillo J., Rojas R. and Ouassini A. (2009), Drin pesticides removal from aqueous solutions using acidtreated date stones, Bioresource Technology, 100, 26762684.

Boussahel R., Bouland S., Moussaoui K.M. and Montiel A. (2000), Removal of pesticide residues in water using the nanofiltration process, Desalination, 132, 205-209.

Brunauer C., Emmett S.P.H. and Teller E. (1938), Adsorption of gases in multimolecular layers, Journal of the American Chemical Society, 60, 309-319.

Chen C., Liang M., Alegre M.R., Durgbanshi A., Bose D., Mourya K.S., Romero J.E. and Carda-Broch S. (2012), Micellar Liquid Chromatographic Determination of Carbaryl and 1-Naphthol in Water, Soil, and Vegetables, International journal of analytical chemistry, 2012.

Chen H., Xiaomin H., Xingmin R., Wenli C., Peng C., Wei L., Shengqing L.i. and Qiaoyun H. (2009), Adsorption and biodegradation of carbaryl on montmorillonite, kaolinite and goethite, Applied clay science, 46, 102-108.

Chowdhury A. Z., Jahan S. A., Islam M.N., Moniruzzaman M., Alam M.K., Zaman M.A., Karim N. and Gan S.H. (2012), Occurrence of organophosphorus and carbamate pesticide residues in surface water samples from the Rangpur district of Bangladesh, Bulletin of environmental contamination and toxicology, 89, 202-207.

Dong J., Tao L., Xiaomeng M., Jianying Z., Kun S., Shiyun A. and Shenglong C. (2012), Amperometric biosensor based on immobilization of acetylcholinesterase via specific binding on biocompatible boronic acid-functionalized Fe@ Au magnetic nanoparticles, Journal of Solid State Electrochemistry, 16, 3783-3790.

Freundlich H. and Hatfield H.S. (1926), Colloid and capillary chemistry.

Ghauch A., Gallet C., Charef A., Rima J. and Bouyer M. (2001), Reductive degradation of carbaryl in water by zero-valent iron, Chemosphere, 42, 419-424.

Gupta, V.K., Gupta B., Rastogi A., Agarwal Sh. and Nayak A. (2011), Pesticides removal from wastewater by activated carbon prepared from waste rubber tire, Water Research, 45, 40474055.

Hamadi N.K., Swaminathan S. and Chen X.D. (2004), Adsorption of paraquat dichloride from aqueous solution by activated carbon derived from used tires, Journal of Hazardous Materials, 112, 133-141.

Hameed B.H., Salman J.M. and Ahmad A.L. (2009), Adsorption isotherm and kinetic modeling of 2, 4-D pesticide on activated carbon derived from date stones, Journal of hazardous materials, 163, 121-126.

Jiang, C.J.C., Chen M.C.M., Xuan S.X.S., Jiang W.J.W., Gong X.G.X. and Zhang Z.Z.Z. (2009), Magnetic separable PSA@ $\mathrm{Fe}_{3} \mathrm{O}_{4} / \mathrm{Ag}$ composites-Fabrication and catalytic properties, Canadian Journal of Chemistry, 87, 502-506.

Kakavandi, B., Jonidi Jafari A., Rezaei Kalantary R., Nasseri S., Ameri A. and Esrafily A. (2013), Synthesis and properties of $\mathrm{Fe}_{3} \mathrm{O}_{4}$-activated carbon magnetic nanoparticles for removal of aniline from aqueous solution: equilibrium, kinetic and thermodynamic studies, Iranian Journal of Environmental Health Science \& Engineering, 10, 19-19.
Kusvuran E., Yildirim D., Mavruk F. and Ceyhan M. (2012), Removal of chloropyrifos ethyl, tetradifon and chlorothalonil pesticide residues from citrus by using ozone, Journal of hazardous materials.

Liu S., Zheng Z. and Li X. (2013), Advances in pesticide biosensors: current status, challenges, and future perspectives, Analytical and Bioanalytical Chemistry, 405, 63-90.

Liu Z. M, Xiao H. Z., Wei H. L., Chun W. and Zhi W. (2009), Novel method for the determination of five carbamate pesticides in water samples by dispersive liquid-liquid microextraction combined with high performance liquid chromatography, Chinese Chemical Letters, 20, 213-216.

Mahapatra A., Mishra B.G. and Hota G. (2013), Electrospun $\mathrm{Fe}_{2} \mathrm{O}_{3}-\mathrm{Al}_{2} \mathrm{O}_{3}$ nanocomposite fibers as efficient adsorbent for removal of heavy metal ions from aqueous solution, Journal of hazardous materials, 258, 116-123.

Mahmoud E.I., Said O.A., Samir Q., Abaamrane A., Assabbane A. and Douch J. (2013) Removal of carbaryl pesticide from aqueous solution by adsorption on local clay in Agadir, American Journal of Analytical Chemistry, 4, 72.

Mahmoud El.O., Alahiane S., Qourzal S., Abaamrane A., Assabbane A. and Douch J. (2013), Removal of Carbaryl Pesticide from Aqueous Solution by Adsorption on Local Clay in Agadir, American Journal of Analytical Chemistry, 4, 72-79.

Mekhloufi M., Zehhaf A., Benyoucef A., Quijada C. and Morallon E. (2013), Removal of 8-quinolinecarboxylic acid pesticide from aqueous solution by adsorption on activated montmorillonites, Environmental monitoring and assessment, 185, 365-375.

Melchert W.R. and Rocha F.R.P. (2010), A greener and highly sensitive flow-based procedure for carbaryl determination exploiting long pathlength spectrophotometry and photochemical waste degradation, Talanta, 81, 327-333.

Meyers N.L., Ahlrichs J.L., and White J.L. (2013), Adsorption of Insecticides on Pond Sediments and Watershed Soils, Proceedings of the Indiana Academy of Science, 432-438.

Mi, H., Xu Y., Shi W., Yoo H., Chae O.B. and Oh S.M. (2011), Flocculant-assisted synthesis of $\mathrm{Fe}_{2} \mathrm{O}_{3}$ carbon composites for superior lithium rechargeable batteries, Materials Research Bulletin.

Ofomaja A.E., Unuabonah E.I. and Oladoja N.A. (2010), Competitive modeling for the biosorptive removal of copper and lead ions from aqueous solution by Mansonia wood sawdust, Bioresource Technology, 101, 3844-3852.

Prucek R., Tuček J., Kilianová M., Panáček A., Kvítek L., Filip J., Kolář M., Tománková K. and Zbořil R. (2011), The targeted antibacterial and antifungal properties of magnetic nanocomposite of iron oxide and silver nanoparticles, Biomaterials, 32, 4704-4713.

Sahoo N.G., Sravendra R., Jae W. Ch., Lin L. and Siew H.Ch. (2010), Polymer nanocomposites based on functionalized carbon nanotubes', Progress in Polymer Science, 35, 837-867.

Salman J.M. and Hameed B.H. (2010), Removal of insecticide carbofuran from aqueous solutions by banana stalks activated carbon, Journal of hazardous materials, 176, 814-819.

Wang Sh., Huimin B., Pengyuan Y. and Gang Ch. (2008), Immobilization of trypsin in polyaniline-coated nano-Fe304 carbon nanotube composite for protein digestion, Analytica Chimica Acta, 612, 182-189.

Wu Q., Chang Q., Wu Ch., Rao H., Zeng X., Wang Ch. and Wang Z. (2010), Ultrasound-assisted surfactant-enhanced 
emulsification microextraction for the determination of carbamate pesticides in water samples by high performance liquid chromatography, Journal of Chromatography A, 1217, 1773-1778.

Wu Q., Guangying Z., Cheng F., Chun W. and Zhi W. (2011), Preparation of a graphene-based magnetic nanocomposite for the extraction of carbamate pesticides from environmental water samples, Journal of Chromatography $A$, 1218, 7936-7942.

Yang K., Wu W., Jing Q. and Zhu L. (2008), Aqueous adsorption of aniline, phenol, and their substitutes by multi-walled carbon nanotubes, Environmental science \& technology, 42, 79317936.

Zhang P., Sun H., Yu L. and Sun T. (2012), Adsorption and Catalytic Hydrolysis of Carbaryl and Atrazine on Pig Manure-Derived Biochars: Impact of Structural Properties of Biochars, Journal of Hazardous Materials.

Zhu Sh.H., Wu H.L., Xia A.L., Nie J.F., Bian Y.C., Cai C.B. and Yu R.Q. (2009), Excitation-emission-kinetic fluorescence coupled with third-order calibration for quantifying carbaryl and investigating the hydrolysis in effluent water, Talanta, 77, 1640-1646. 